\title{
Distribuição natural e habitat da araucária frente às mudanças climáticas globais
}

\author{
Marcos Silveira Wrege ${ }^{1 *}$, Elenice Fritzsons ${ }^{1}$, Márcia Toffani Simão Soares ${ }^{1}$, Itamar Antônio Bognola ${ }^{1}$, Valderês Aparecida de Sousa ${ }^{1}$, \\ Letícia Penno de Sousa ${ }^{2}$, João Bosco Vasconcellos Gomes ${ }^{1}$, Ananda Virgínia de Aguiar ${ }^{1}$, Gustavo Crizel Gomes², \\ Maria de Fátima Silva Matos ${ }^{1}$, Andressa Godinho Scarante ${ }^{3}$, Rogério Soares Ferrer ${ }^{4}$ \\ ${ }^{1}$ Embrapa Florestas, Estrada da Ribeira, Km 111, CP 319, CEP 83411-000, Colombo, PR, Brasil \\ ${ }^{2}$ Embrapa Clima Temperado, Rodovia BR 392, Km 78, CP 403, CEP 96010-970, Pelotas, RS, Brasil \\ ${ }^{3}$ Pontifícia Universidade Católica do Paraná, Rua Imaculada Conceição, 1155, Prado Velho, CEP: 80215-901, Curitiba, PR, Brasil \\ ${ }^{4}$ Universidade Católica de Pelotas, Rua Gonçalves Chaves, 373, CEP 96015-560, Pelotas, RS, Brasil
}

*Autor correspondente:

marcos.wrege@embrapa.br

Termos para indexação:

Conservação genética

Aquecimento global

Distribuição geográfica

Index terms:

Genetic conservation

Global warming

Geographical distribution

Recebido em 20/02/2017

Aprovado em 23/08/2017

Publicado em 29/09/2017

doi: 10.4336/2017.pfb.37.91.1413
Resumo - A araucária (Araucaria angustifolia (Bertol.) O. Kuntze.), conhecida como pinheiro-do-paraná, é uma espécie florestal nativa do Brasil, adaptada às regiões serranas frias e úmidas do sul e do sudeste do país e torna-se vulnerável diante das mudanças climáticas globais. Apresenta grande valor econômico, social e ambiental, pois é uma das espécies nativas com maior incremento e potencial de ganho genético, apresenta excelente qualidade de madeira e ainda produz sementes que podem ser usadas na alimentação humana e animal. Com o objetivo de conhecer a distribuição natural atual e o habitat das populações, percorremos parte das bordas da região de ocorrência da araucária, marcando a posição geográfica e altitude. Com as informações de campo, juntamente com dados secundários do Centro de Informações Ambientais (CRIA), mapeamos a distribuição da araucária no presente e simulamos para as próximas décadas, considerando a projeção de cenários climáticos futuros. Estes estudos são essenciais para a melhor compreensão dos riscos de extinção e das medidas mitigadoras que poderiam ser adotadas para reduzir os impactos das mudanças climáticas globais sobre a espécie, contribuindo, dessa maneira, para a sua conservação.

\section{Distribution and habitat of brazilian-pine according to global climate change}

\begin{abstract}
Araucaria angustifolia (Bertol.) O. Kuntze., also known as brazilian-pine, is a forest native species from Brazil. A. angustifolia is more vulnerable to global climate change, considering it is living in cold and humid mountain regions from southern and southeastern Brazil. Among the native Brazilian forest species, it presents one of the greatest growth and genetic gain potential. It shows excellent wood quality and can still be used in human and animal food, presenting great economic, social and environmental value. In order to determine current distribution of the species and better know its habitat, we worked in the regions representing the borders of natural occurrence, identifying populations and getting trees altitude and geographycal position. Field information along with secondary data from the Environmental Information Center (CRIA) were used to map current distribution of brazilian-pine and to project the distribution in the next decades, with the projection of future climate scenarios. Mapping studies of ecological niches in present and future climate scenarios characterizing the environments in which they are living is essential for a better understanding of the risks of species extinction and which mitigating measures could be adequate to reduce the impacts of global climate change on species, thus contributing to the conservation and knowledge of this important species.
\end{abstract}




\section{Introdução}

A araucária (Araucaria angustifolia (Bertol.) O. Kuntze.) é a espécie florestal nativa mais representativa das regiões serranas frias e úmidas do sul e do sudeste do país. Apresenta grande importância econômica, social e ambiental. Dentre as espécies nativas do Brasil, está entre as que têm maior crescimento e potencial de ganho genético, com excelente qualidade de madeira. Os pinhões são muito apreciados na culinária local e consumidos por muitas espécies da fauna, dentre as quais se destacam a cutia (Dasyprocta spp.) e a gralhaazul (Cyanocorax caeruleus), animais estocadores de alimentos, que enterram os pinhões para comê-los posteriormente, atuando como dispersores (Anjos, 1991; Lamberts, 2003).

Apesar de sua importância, os remanescentes da Floresta com Araucária não representam mais que 7\% da área original no Brasil (Wrege et al., 2015). Hoje, a araucária está situada na categoria criticamente em perigo em nível global (Thomas, 2013; IUCN..., 2017), por ter um habitat bastante restrito pela pressão antrópica e, com isso, estar sujeita à forte retração na sua distribuição. Além dos problemas de antropização e fragmentação sofridos com sua exploração no século passado, as mudanças climáticas globais constituem-se em nova ameaça, pois favorecem a expansão das florestas próximas, compostas por espécies folhosas melhor adaptadas ao clima mais quente e com desenvolvimento vegetativo e reprodutivo mais eficientes (Klein, 1960, 1984).

Nos últimos anos, ocorreram grandes mudanças no clima de nosso planeta, muito rápidas e sem precedentes históricos. A década de 2001 a 2010 foi a mais quente já registrada (World Meteorological Organization, 2013), com consequências muito negativas, principalmente para as espécies endêmicas como a araucária, espécie que apresenta ciclo reprodutivo bastante longo, sendo dependente do frio, da umidade e de solos profundos e bem drenados.

No passado, quando o clima era mais frio, $A$. angustifolia era encontrada em uma área bem maior que a atual. Sua ocorrência foi registrada, inclusive, no Nordeste do Brasil, onde foram encontrados fósseis de seus ancentrais que habitaram aquela região há muitos milhões de anos (Conceição et al., 2016). Hoje, com o aumento de temperatura, a tendência é oposta.

As mudanças climáticas poderão ser incompatíveis com as zonas de ocorrência dos biomas. Esses sofrerão com os aumentos de temperatura e as mudanças no regime pluvial, muito além do normal, resultando, em alguns casos, na desertificação ou na savanização. Embora os biomas sofram naturalmente diferentes pressões ambientais e antropização, as mudanças climáticas globais representam uma fonte de pressão adicional, tornando o cenário da existência ainda mais complexo (Navas \& Cruz Neto, 2008).

Desse modo, o mapeamento dos cenários futuros, prevendo as zonas de ocorrência da araucária nas próximas décadas, é importante para auxiliar na preservação da espécie. Para esse fim, a modelagem da predição de ocorrência da espécie é a técnica recomendada. A finalidade dessa análise é estabelecer uma ligação entre a distribuição da espécie e as variáveis ambientais, a fim de representar as condições favoráveis para sua ocorrência e, com isso, auxiliar na análise das consequências das mudanças climáticas globais sobre sua distribuição e estabelecer ações mitigadoras que levem à preservação ou conservação das diferentes populações de araucária.

Assim, o objetivo desse trabalho é mostrar os avanços ocorridos no mapeamento das regiões de ocorrência natural da araucária e apresentar os efeitos das mudanças climáticas globais sobre essas regiões. Com base nessas informações, pretende-se gerar subsídios úteis para proteção e conservação da espécie em longo prazo, utilizando para isso as ferramentas mais modernas de predição de ocorrência de espécie, de sistemas de informações geográficas associadas à genotipagem, dendrocronologia, estudos de solos e de clima. Com as evoluções no mapeamento da distribuição da espécie, pode-se facilitar a busca de material genético em campo para uso em programas de melhoramento genético e de conservação genética, indicar os melhores locais para plantios com diversos fins ou ainda para conservação in situ da espécie, o que poderá representar um grande avanço para a sua preservação.

\section{Histórico das delimitações das regiões de ocorrência natural de $\boldsymbol{A}$. angustifolia}

O primeiro mapeamento que caracterizou a região de ocorrência de araucária foi feito em 1953, pelo professor visitante do Departamento de Botânica da Universidade de São Paulo (USP), Prof. Dr. Kurt Hueck, na seguinte publicação: "Distribuição e habitat natural do Pinheiro do Paraná" (Hueck, 1953). Anteriormente, foram feitos outros mapeamentos, mas com discordância quanto à região de ocorrência da espécie. Os primeiros foram 
feitos por Paulino Cavalcanti, em 1908 (Cavalcanti, 1908); por Karl Rühle, em 1928 (Rühle, 1928); por Preston James, em 1942 (James, 1942) e por Hammond (s/d) (Hueck, 1953) (Figuras 1 e 2).

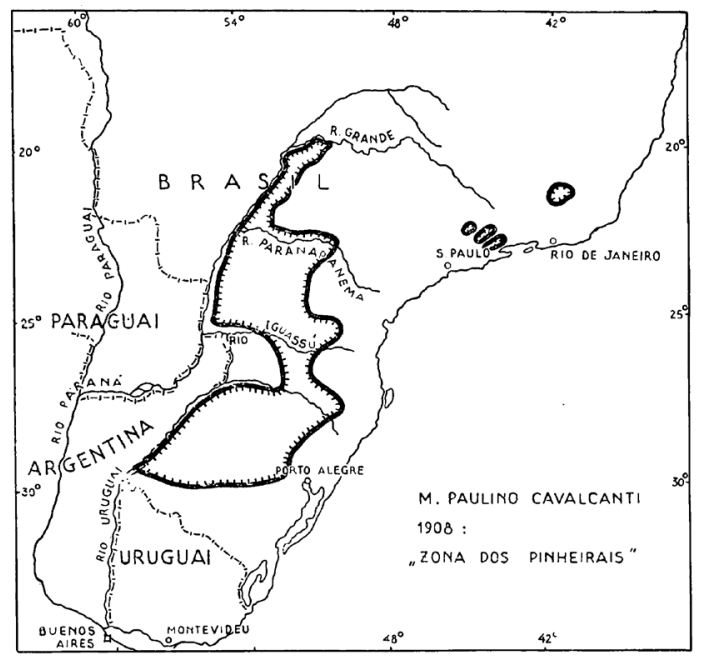

(a)

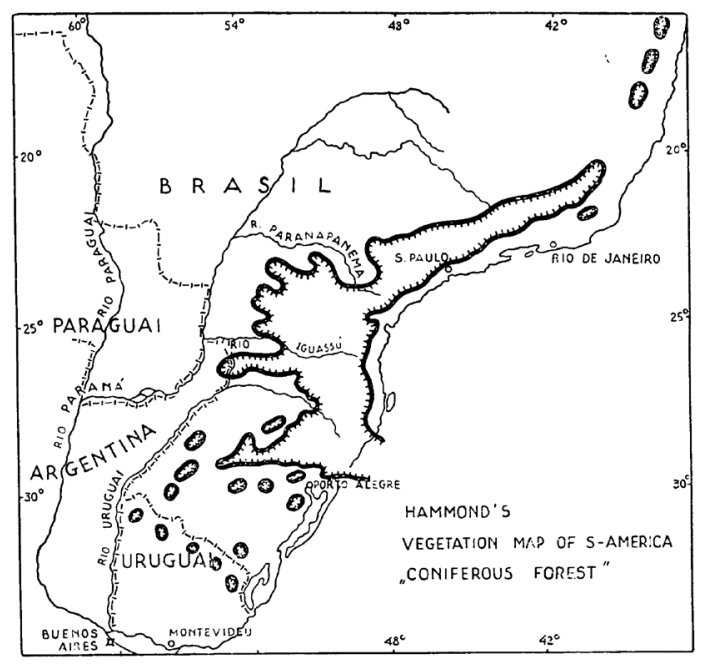

(c)
Hueck (1953) foi quem fez a melhor caracterização das zonas de ocorrência de araucária na época e o seu trabalho é ainda muito citado até os dias de hoje.

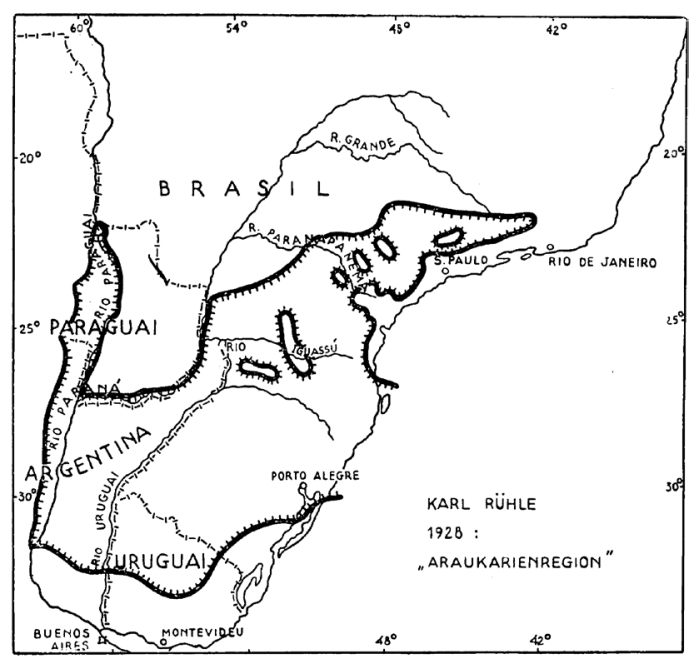

(b)

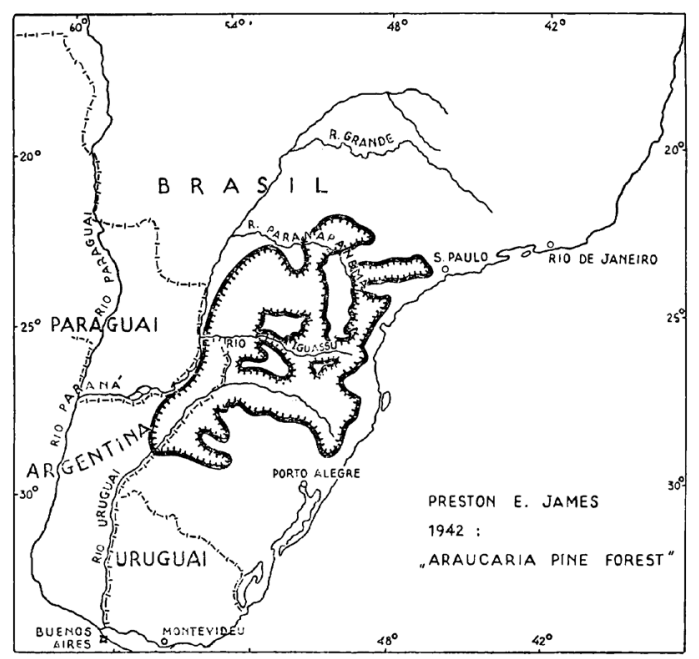

(d)

Figura 1. Evolução dos mapeamentos das regiões de ocorrência de Araucaria angustifolia, feitos por a) Cavalcanti, b) Rühle, c) Hammond e d) James. Fonte: Hueck (1953).

Hueck (1953) fez observações sobre a substituição das Florestas com Araucária pelas matas úmidas subtropicais, onde ambos os tipos florestais entram em contato. Fez observações sobre a substituição gradativa do campo pela Floresta com Araucária, em função da mudança de um clima mais frio e seco no passado para um clima mais úmido no presente (últimos 10.000 anos, desde o Holoceno). Da mesma forma, observou que a floresta subtropical úmida avançou sobre a Floresta com
Araucária e, nas zonas em que a floresta subtropical úmida não penetrou ainda, a araucária é a espécie de domínio exclusivo da paisagem.

Nos meados do século passado, não se falava ainda em mudanças climáticas globais. A araucária já era muito explorada, reduzindo rapidamente as populações da espécie. Naquela época, já havia a preocupação com a extinção, dada a rapidez com que a espécie era explorada (Hueck, 1953). 


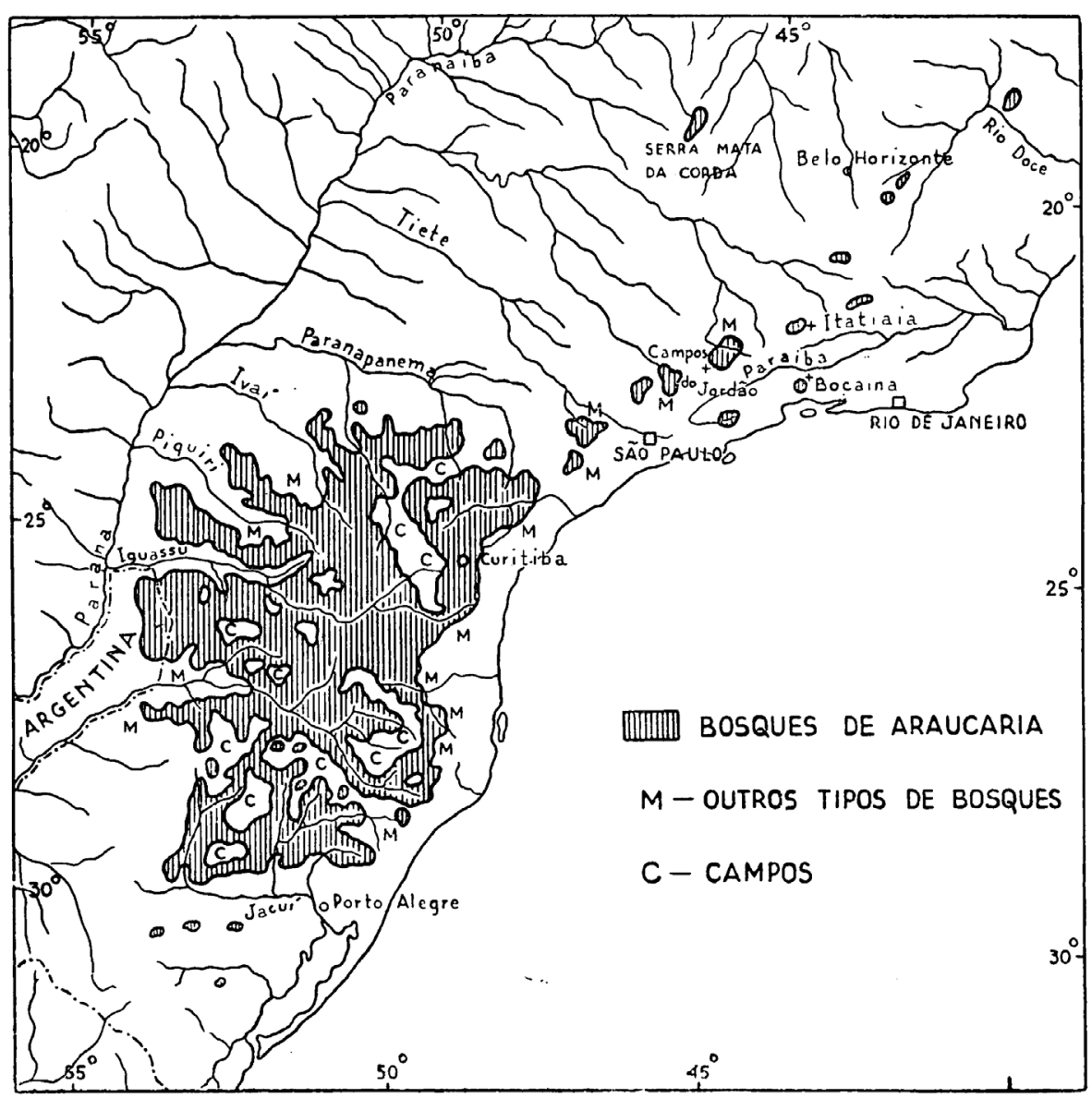

Figura 2. Regiões de distribuição de A. angustifolia, segundo Hueck (1953).

Em 2009, Wrege et al. (2009) mapearam a ocorrência da araucária no presente e nos cenários de mudanças climáticas (Figura 3). Os autores usaram um modelo simplificado, sem os cenários climáticos futuros elaborados pelo Painel Intergovernamental de Mudanças Climáticas (IPCC), pois ainda não se encontravam disponíveis. O método usado consistiu em aumentar a temperatura diária das séries climáticas históricas do período base 1961-1990 nos estados do Paraná, Santa Catarina, Rio Grande do Sul e São Paulo, de forma uniforme e constante, em $1{ }^{\circ} \mathrm{C}, 2{ }^{\circ} \mathrm{C}$ e $3{ }^{\circ} \mathrm{C}$. Foram feitas isolinhas indicando as classes favoráveis ao desenvolvimento da araucária para o período correspondente ao presente. Os valores das isolinhas foram obtidos com base em informações de literatura, verificando quais temperaturas eram favoráveis ao desenvolvimento da araucária. Os mesmos valores de isolinhas foram usados para os mapas feitos com os aumentos de temperatura citados anteriormente, feitos para representar os aumentos de temperatura previstos para ocorrer até o final do século, em 2100. Neste estudo, foi observada redução na área de ocorrência de araucária no país. Além disso, com o aumento de temperatura ocorreu um deslocamento das zonas de araucária para regiões de maiores altitude e latitude, onde permaneceram as menores temperaturas. Foi o primeiro trabalho feito no Brasil com projeções futuras de ocorrência de araucária. No entanto, a região de ocorrência de araucária ficou subestimada nos limites extremos de sua ocorrência, nos estados de São Paulo e do Rio Grande do Sul e, praticamente, não indicou as regiões de ocorrência nos estados de Minas Gerais, Rio de Janeiro e Espírito Santo (Figura 3). 


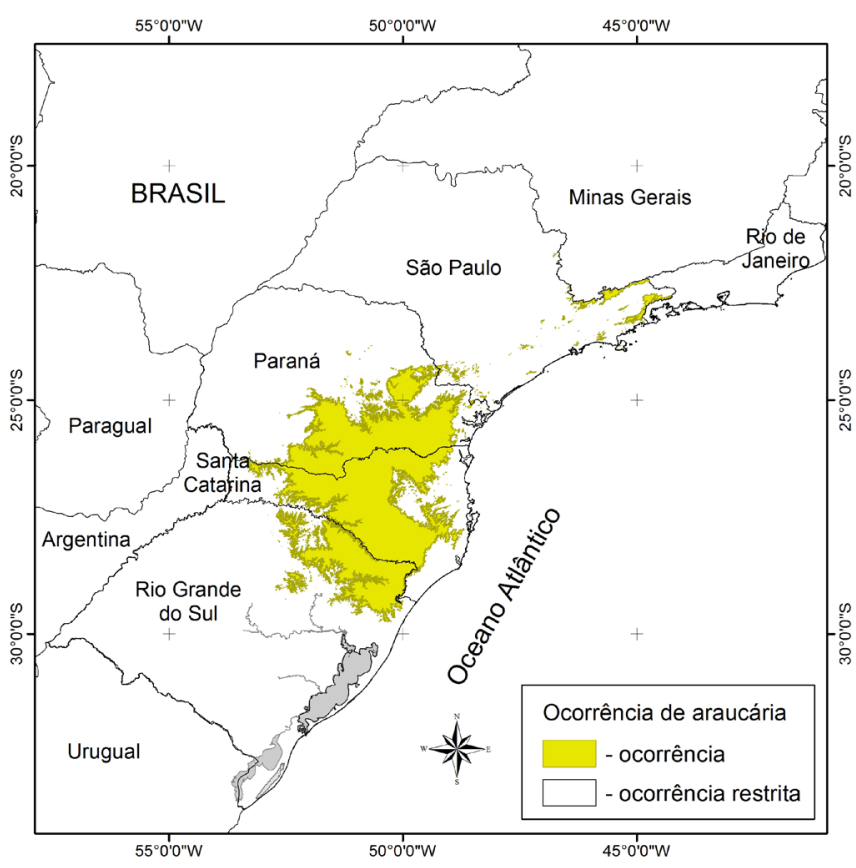

Figura 3. Regiões de ocorrência de $A$. angustifolia, segundo Wrege et al. (2009).

\section{Nicho de ocorrência de $A$. angustifolia no presente e nos cenários de mudanças climáticas projetadas para as próximas décadas}

Com os modelos computacionais existentes hoje, as ferramentas disponíveis para modelagem de nicho ecológico e a disponibilidade de dados secundários de acesso livre e gratuito pela internet, entre os quais os dados de coleções biológicas do Centro de Referência em Informação Ambiental (CRIA) (2015), é possível fazer predições de ocorrência de qualquer espécie brasileira com maior acurácia, utilizando camadas de informações ambientais (solos, clima e relevo). No trabalho de Wrege et al. (2016), foram usados dados primários, obtidos em campo com GPS, e dados secundários do CRIA. Foram usados mapas feitos do período atual (Wrege et al., 2011) e de períodos futuros, de acordo com cenários climáticos futuros do IPCC, organizados e compilados por Chou et al. (2014a), que trabalhou com dados do Instituto Nacional de Pesquisas Espaciais (INPE). Utilizando a modelagem de nicho, Wrege et al. (2016) obtiveram os mapas apresentados nas Figuras 4 a 10. Neste trabalho, a simulação das áreas com potencial para ocorrência de araucária no período atual foi significativa $(\mathrm{p}<0,001)$, apresentando elevados valores de AUC $(0,9 \pm 0,001)$ e erro de omissão de $0 \%$.

Nas análises preliminares, foram utilizados somente os dados das variáveis climáticas. As áreas com cores amarelas nos mapas (Figuras 9 e 10) representaram as regiões de ocorrência atual de araucária, definidas pelos modelos Niche Mosaic e Bioclim, enquanto que as regiões nas cores brancas representaram as áreas com potencial de ocorrência restrita, pelo fato de não reunirem as características climáticas necessárias para o desenvolvimento pleno da espécie. Nessas áreas, no entanto, a araucária pode ocorrer em locais com microclimas específicos. O mesmo critério foi adotado para os mapas representativos dos cenários climáticos futuros (Figuras 11 a 16), que representaram as regiões com potencial para desenvolvimento da araucária nos períodos 2011-2040, 2041-2070 e 2071-2100, em dois cenários diferentes, com tendências de concentração de GEEs (Representative concentration pathways) - RCP $=4,5$, medianamente pessimista, e RCP $=8,5$, mais pessimista (Chou et al., 2014b).

No mapeamento da distribuição da araucária no Brasil (Figuras 9 e 10) feito em 2016 (Wrege et al., 2016), houve avanços significativos daquele realizado em 2009 (Wrege et al., 2009) (Figura 3), principalmente nas bordas de ocorrência, apresentando evoluções na região Sudeste, com zonas representativas de ocorrência nos estados de São Paulo, Minas Gerais e Rio de Janeiro, estados pouco representados anteriormente. Houve melhoras também na representação do estado do Rio Grande do Sul, incluindo os municípios do extremo Sul: Santana da Boa Vista, Pelotas e Canguçu (Figura 8). O mapa das regiões de ocorrência de araucária no Sul do país (Figuras 9 e 10) ficou semelhante ao proposto em 1953, por Hueck (Figura 2). Nos mapas de Hueck, no entanto, a região sudeste foi pouco representada, bem como a metade sul do Rio Grande do Sul.

Alguns autores ressaltam a presença de $A$. angustifolia em áreas fora do núcleo principal, marcadamente na Serra do Sudeste, estado do Rio Grande do Sul, região florística e geologicamente diferente do Planalto SulBrasileiro, considerando-a como relíquia de climas anteriores mais secos (Hueck, 1953, 1972; Rambo, 1951; Leite, 2002). Este caráter relictual foi corroborado por estudos de pólen acumulado em turfeiras (Behling et al., 2004, 2016). Lima et al. (2002) também reconhecem a existência de matas de araucária em áreas no sul do Rio Grande do Sul. 


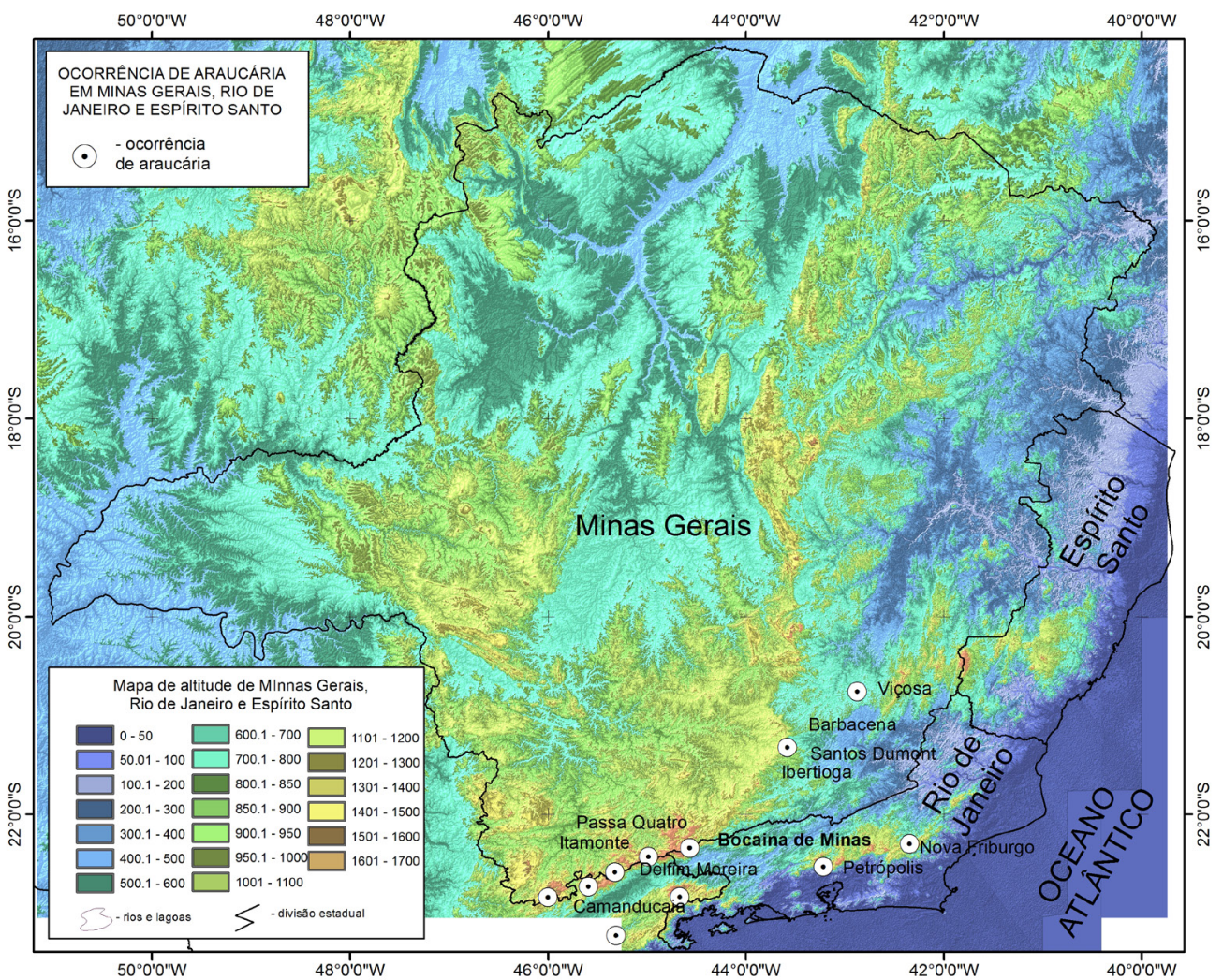

Figura 4. Locais de ocorrência de araucária nos estados de Minas Gerais e Rio de Janeiro e mapa de altitude. Elaborado a partir do banco de dados da Embrapa (Projeto Araucamate), banco de dados do CRIA (Centro de Referência em Informação Ambiental, 2015) e do GTOPO30 (Geological Survey, 1999).

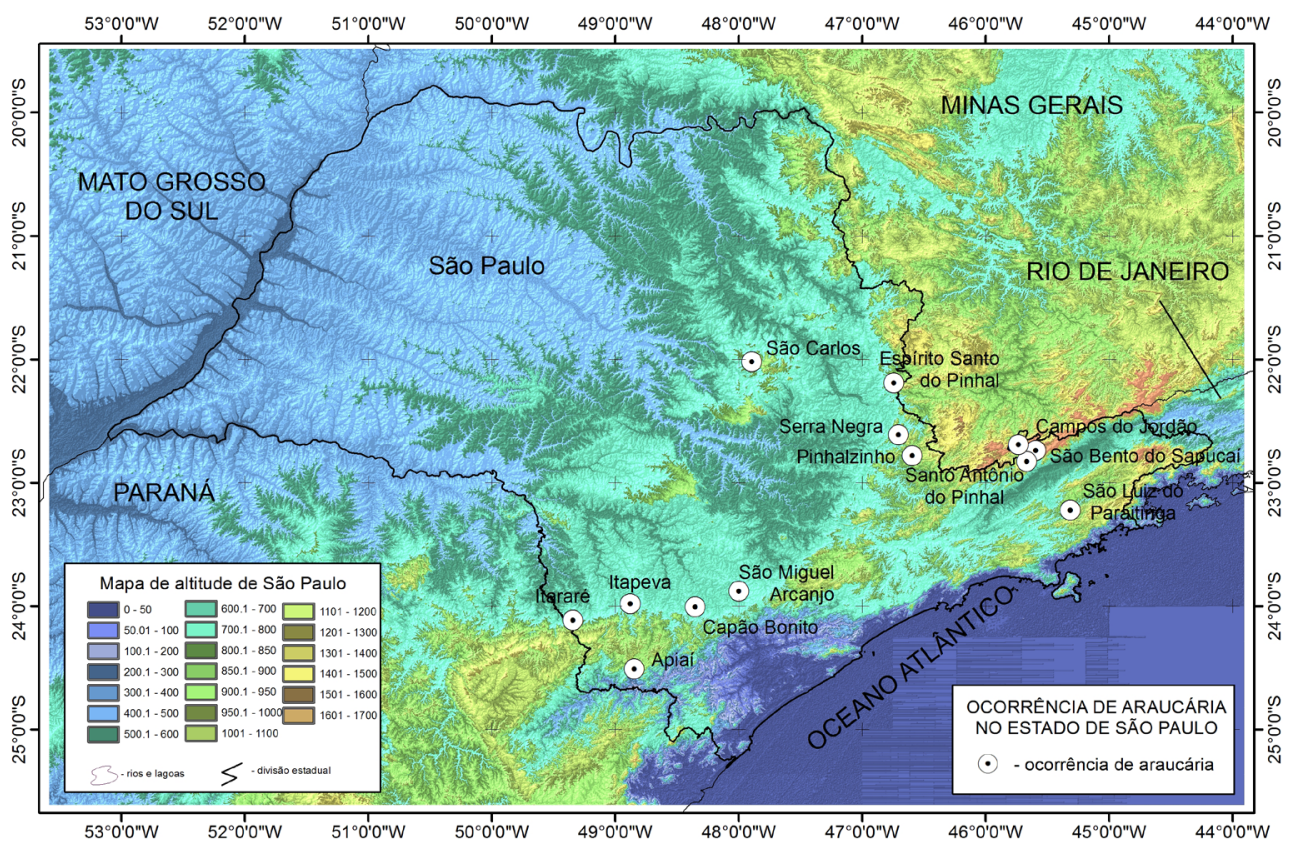

Figura 5. Locais de ocorrência de araucária em São Paulo e mapa de altitude. Elaborado a partir do banco de dados da Embrapa (Projeto Araucamate), banco de dados do CRIA (Centro de Referência em Informação Ambiental, 2015) e do GTOPO30 (Geological Survey, 1999). 


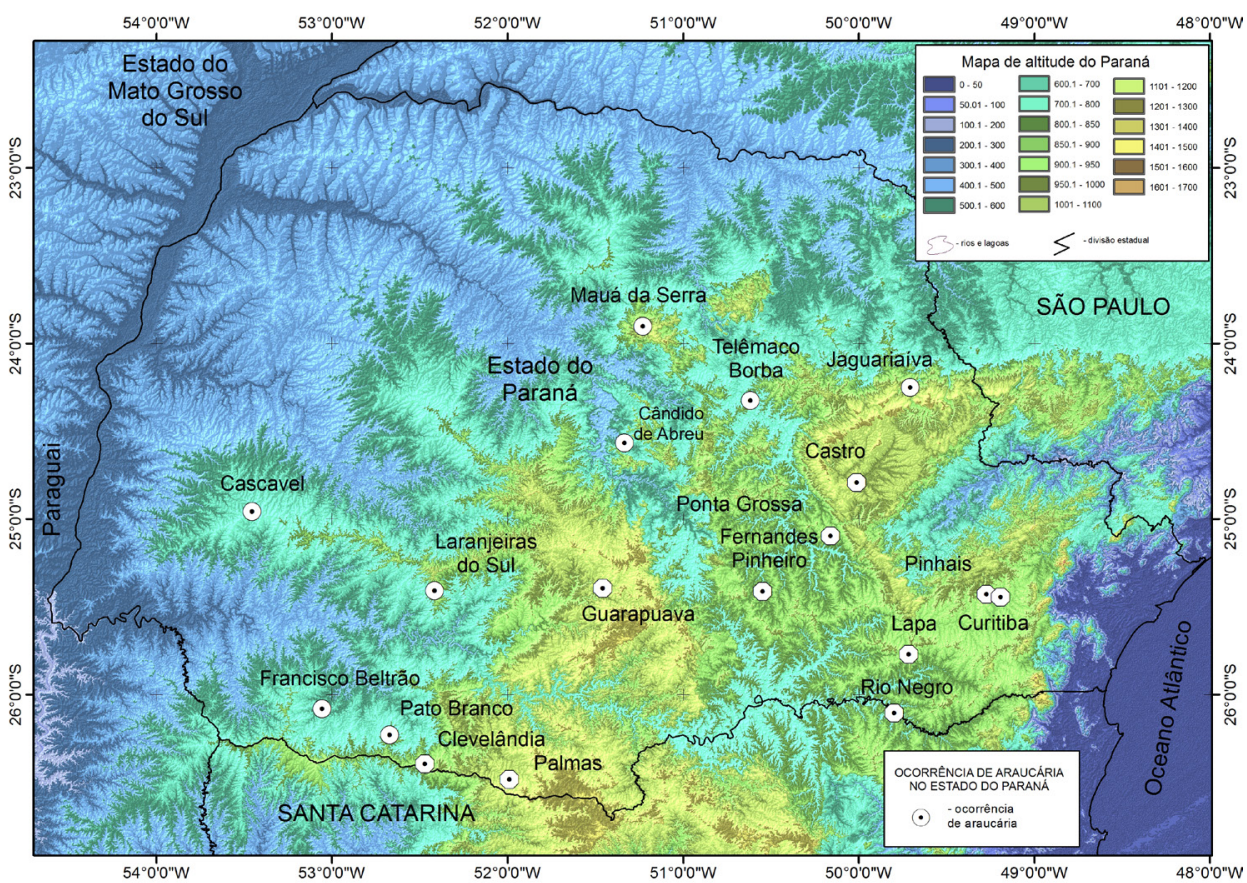

Figura 6. Locais de ocorrência de araucária no Paraná e mapa de altitude. Elaborado a partir do banco de dados da Embrapa (Projeto Araucamate), banco de dados do CRIA (Centro de Referência em Informação Ambiental, 2015) e do GTOPO30 (Geological Survey, 1999).

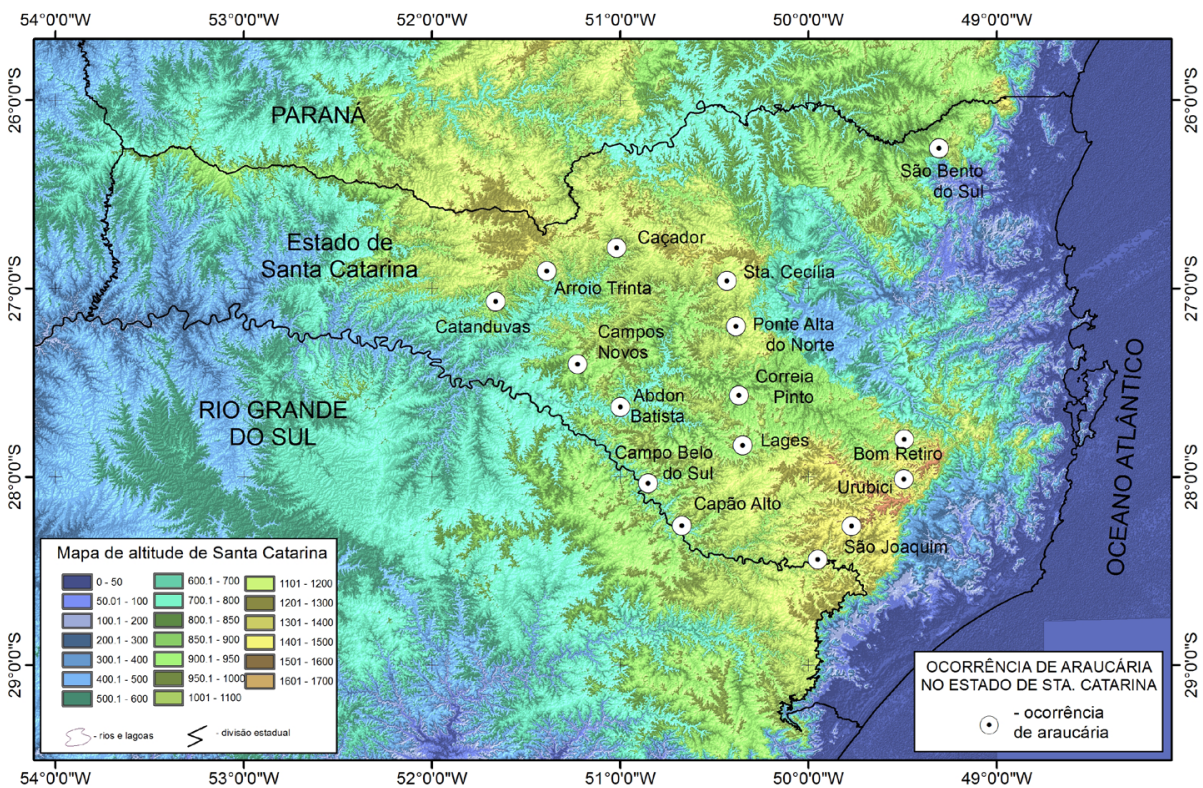

Figura 7. Locais de ocorrência de araucária em Santa Catarina e mapa de altitude. Elaborado a partir do banco de dados da Embrapa (Projeto Araucamate), banco de dados do CRIA (Centro de Referência em Informação Ambiental, 2015) e do GTOPO30 (Geological Survey, 1999). 


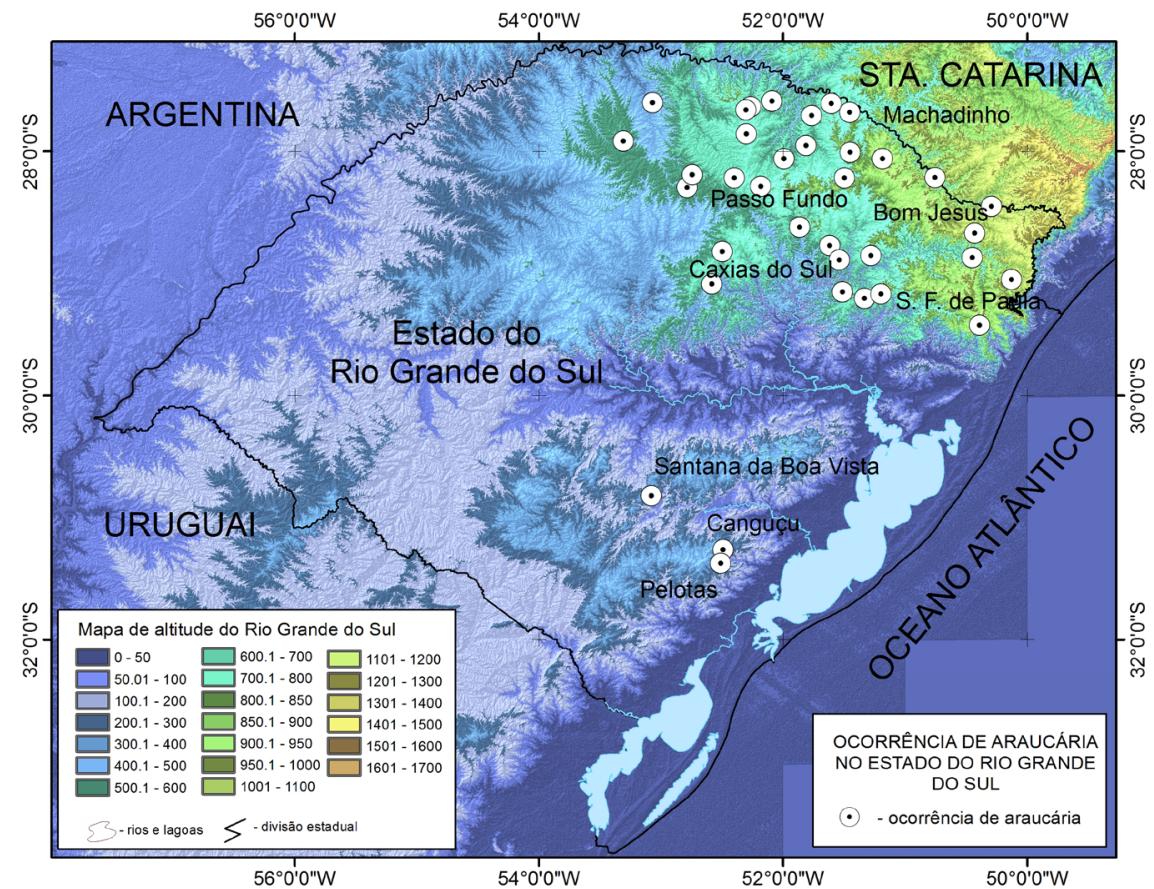

Figura 8. Locais de ocorrência de araucária no Rio Grande do Sul e mapa de altitude. Elaborado a partir do banco de dados da Embrapa (Projeto Araucamate), banco de dados do CRIA (Centro de Referência em Informação Ambiental, 2015) e do GTOPO30 (Geological Survey, 1999).

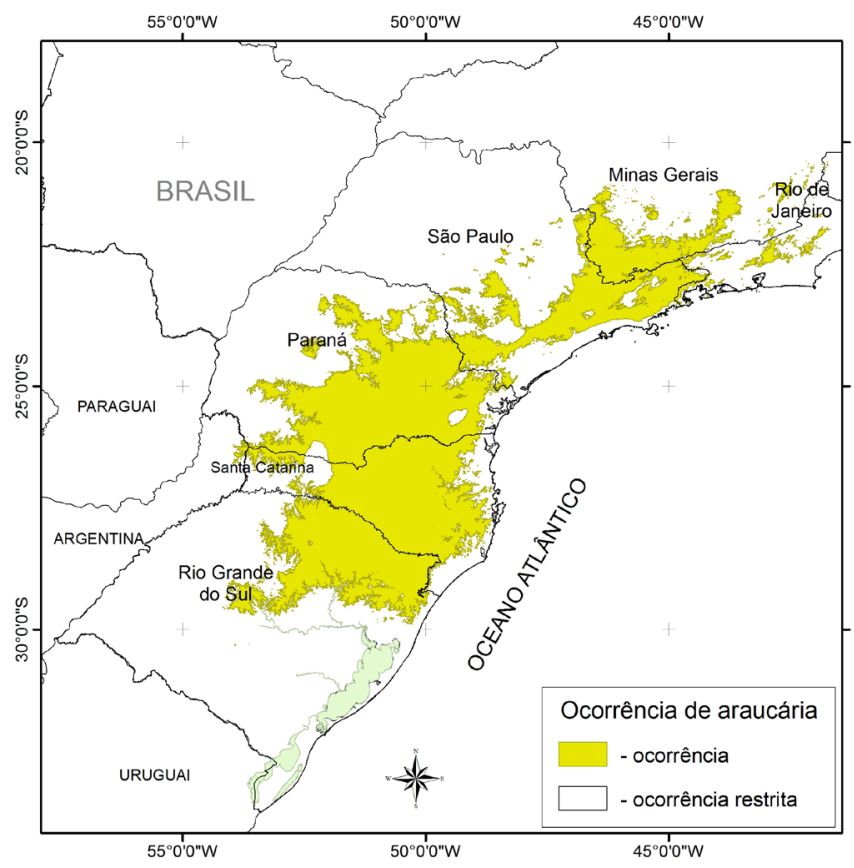

Figura 9. Nicho fundamental de ocorrência de araucária baseado no modelo Bioclim, segundo Wrege et al. (2016). Nota: Latitude original: $0^{\circ}$ Equador, Longitude original: 54 ${ }^{\circ}$ Sul, Datum: SAD69. Fonte: Divisas: IBGE (2011), Modelo digital de elevação: Geological Survey (1999), dados climáticos: INPE.

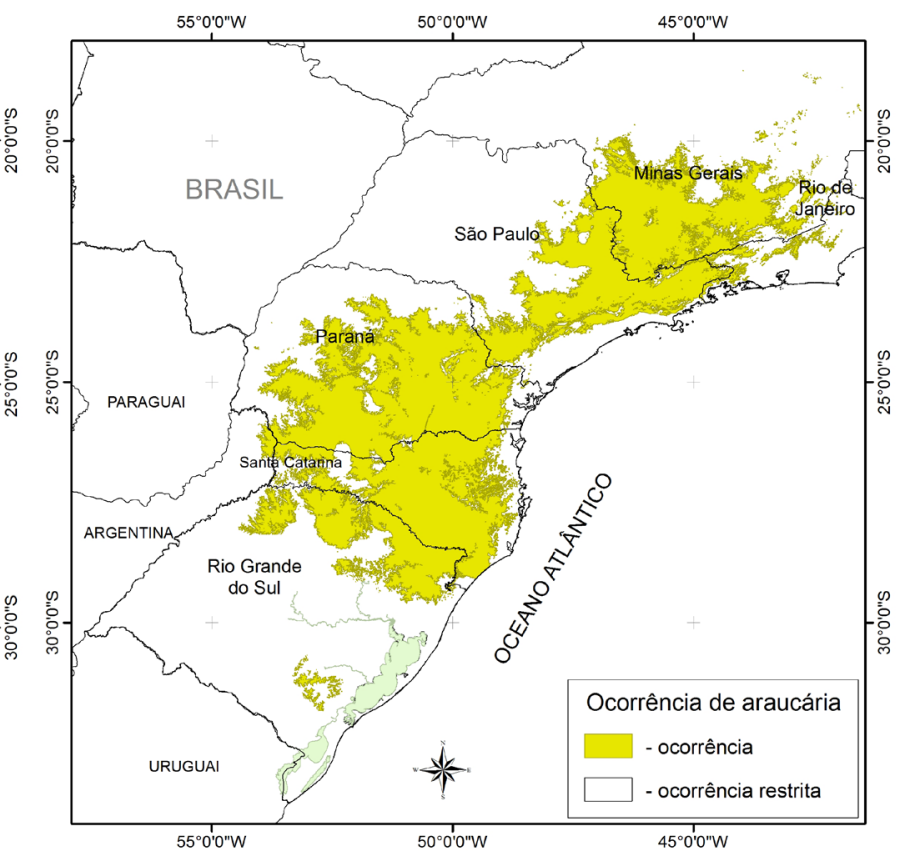

Figura 10. Nicho fundamental de ocorrência de araucária baseado no modelo Niche Mosaic, segundo Wrege et al. (2016). Nota: Latitude original: $0^{\circ}$ Equador, Longitude original: 54 ${ }^{\circ}$ Sul, Datum: SAD69. Fonte: Divisas: IBGE (2011), Modelo digital de elevação: Geological Survey (1999), dados climáticos: INPE. 
Segundo Dutra \& Stranz (2003), embora ainda não existam dados suficientes para confirmar seu caráter nativo, a análise fitossociológica preliminar e as condições edáficas (solos ácidos) e climáticas (temperaturas médias mais baixas) mostram muitos aspectos similares aos presentes no Planalto SulBrasileiro. Da mesma forma, Gonçalves \& Souza (2014) apontam similaridades florísticas e espécies indicadoras de florestas mistas em parcelas localizadas ao sul da Encosta da Serra do Sudeste.

Teixeira et al. (1986) registraram núcleos com coníferas em alguns municípios da metade sul do Rio Grande do Sul, entre os quais Santana da Boa Vista, Dom Feliciano, Cachoeira do Sul e Canguçu. Reitz et al. (1988) comentaram sobre núcleos de 'pinheiros' em São Lourenço do Sul e Canguçu, considerando o último como o maior da região, com área originalmente de $90 \mathrm{~km}^{2}$. De forma geral, os autores sempre relacionaram a presença não apenas de $A$. angustifolia como de Podocarpus lambertii em altitudes maiores que $400 \mathrm{~m}$. Na região meridional do Rio Grande do Sul, as duas espécies ocorrem numa faixa altitudinal mais baixa, sob condições de menor pluviosidade e em solos predominantemente litólicos (Teixeira et al., 1986).

Mais recentemente, alguns autores realizaram estudos em regiões com presença de coníferas nativas, mas fora da área núcleo que equivaleria à Floresta com Araucária. Dümig et al. (2008) estudaram a dispersão das florestas com A. angustifolia sobre os campos. Carlucci et al. (2011) relatam a ocorrência de espécies típicas das Florestas com Araucária no Planalto Sul-Brasileito em áreas da Serra do Sudeste, sugerindo uma ocorrência disjunta da espécie e da própria formação florestal, considerando-as como formações naturais. Giongo \& Waechter (2007) estudaram a composição florística de regiões com formações savanóides com a presença destas coníferas na Serra do Sudeste. Behling \& Pillar (2007) e Duarte et al. (2007) realizaram estudos sobre a expansão desta espécie sobre áreas campestres e mosaicos campo-floresta, enquanto que Carlucci et al. (2012) realizaram estudos em áreas de transicão floresta-campo com presença de A. angustifolia na Serra do Sudeste.

\section{Condições do clima onde $\boldsymbol{A}$. angustifolia se desenvolve}

A araucária ocorre, com maior frequência, nas regiões serranas de clima frio e úmido do sul do Brasil e, em menor escala, na região sudeste, em altitudes médias situadas em torno de $1.000 \mathrm{~m}$ (Tabela 1), podendo chegar até pouco mais de $2.400 \mathrm{~m}$. A menor altitude é de $211 \mathrm{~m}$, mas geralmente situa-se acima de 400-500 m, dependendo do local. A média das temperaturas mínimas no inverno é de $9,5^{\circ} \mathrm{C}$, podendo chegar a $-12,9{ }^{\circ} \mathrm{C}$ (média das temperaturas mínimas absolutas) e a média das temperaturas máximas no verão é de $25,9^{\circ} \mathrm{C}$, chegando até aos $40,7{ }^{\circ} \mathrm{C}$ (média das temperaturas máximas absolutas) (Wrege et al., 2011, 2015).

Conforme relatado anteriormente, observa-se a existência de populações naturais de araucária no extremo sul do Rio Grande do Sul, nos municípios de Santana da Boa Vista, Canguçu e Pelotas, sobre a Serra do Sudeste, avançando sobre o campo em pequenos aglomerados, em uma região de Floresta Estacional Semidecidual, presente no Bioma Pampa, em altitudes variando entre $211 \mathrm{~m}$ e $372 \mathrm{~m}$, média da temperatura máxima absoluta variando entre $34,9{ }^{\circ} \mathrm{C}$ e $35,9{ }^{\circ} \mathrm{C}$ no verão, média da temperatura mínima absoluta variando entre $-3,1{ }^{\circ} \mathrm{C} \mathrm{e}-1,0{ }^{\circ} \mathrm{C}$ no inverno e temperatura média anual variando entre $16,8{ }^{\circ} \mathrm{C}$ e $18,0{ }^{\circ} \mathrm{C}$ (Wrege et al., 2011, 2015).

Hueck (1953), nos meados do século passado, utilizou algumas estações meteorológicas situadas em cidades como São Paulo, Curitiba, Blumenau e Porto Alegre, e definiu o clima para a espécie, caracterizando seu ambiente utilizando as temperaturas médias anuais e dos meses mais frio e mais quente do ano.

\section{Área com potencial para ocorrência de $A$. angustifolia no Brasil}

A área total atual, com potencial para ocorrência da espécie, é de pouco mais de 37 milhões de ha, definida pelo modelo Niche Mosaic, ou pouco mais de 29 milhões de ha, definida pelo modelo Bioclim, com maior área na região Sul e menor na região Sudeste do país. Os mapas de ocorrência projetam uma redução expressiva de área potencial para a araucária nas próximas décadas. $\mathrm{O}$ primeiro modelo de cenário climático futuro $(\mathrm{RCP}=$ 4,5), medianamente pessimista, projeta uma redução menor, e o segundo modelo $(\mathrm{RCP}=8,5)$, mais pessimista, projeta uma expressiva redução da área, chegando em 2100 à quase extinção de área com potencial para o desenvolvimento da espécie (Tabela 2).

Pesq. flor. bras., Colombo, v. 37, n. 91, p. 331-346, jul./set. 2017 
Tabela 1. Dados de temperatura nas regiões de ocorrência de araucária.

\begin{tabular}{|c|c|c|c|c|c|c|c|c|c|c|c|c|c|c|c|}
\hline \multirow[t]{2}{*}{ Variável } & \multicolumn{5}{|c|}{ Temperatura média $\left({ }^{\circ} \mathrm{C}\right)$} & \multicolumn{5}{|c|}{ Temperatura mínima $\left({ }^{\circ} \mathrm{C}\right)$} & \multicolumn{5}{|c|}{ Temperatura mínima absoluta $\left({ }^{\circ} \mathrm{C}\right)$} \\
\hline & ver & out & inv & prim & ano & ver & out & inv & prim & ano & ver & out & inv & prim & ano \\
\hline Menor valor & 13,2 & 11,3 & 9,4 & 11,7 & 11,3 & 9,7 & 7,6 & 4,8 & 7,4 & 7,3 & $-0,3$ & $-6,9$ & $-12,9$ & $-7,1$ & $-6,8$ \\
\hline Maior valor & 24,5 & 22,4 & 18,4 & 21,6 & 21,4 & 21,5 & 19,5 & 14,6 & 18,3 & 18,5 & 15,9 & 10,4 & 4,0 & 10,3 & 10,2 \\
\hline Valor médio & 20,0 & 17,4 & 14,0 & 17,3 & 17,2 & 16,2 & 13,6 & 9,5 & 13,0 & 13,1 & 8,7 & 3,1 & $-3,0$ & 2,9 & 2,9 \\
\hline \multirow[t]{2}{*}{ Variável } & \multicolumn{5}{|c|}{ Temperatura máxima $\left({ }^{\circ} \mathrm{C}\right)$} & \multicolumn{5}{|c|}{ Temperatura máxima absoluta $\left({ }^{\circ} \mathrm{C}\right)$} & \multirow{2}{*}{\multicolumn{5}{|c|}{ Altitude (m) }} \\
\hline & ver & out & inv & prim & ano & ver & out & inv & prim & ano & & & & & \\
\hline Menor valor & 19,3 & 17,9 & 15,6 & 18,5 & 18,1 & 26,4 & 24,7 & 24,6 & 28,5 & 23,4 & & & & & 211 \\
\hline Maior valor & 30,6 & 28,7 & 25,7 & 27,9 & 27,5 & 40,7 & 38,4 & 37,5 & 39,0 & 36,5 & & & & & 2.461 \\
\hline Valor médio & 25,9 & 23,8 & 20,8 & 23,5 & 23,5 & 33,4 & 30,9 & 29,4 & 33,5 & 30,5 & & & & & 1.053 \\
\hline
\end{tabular}

Obs.: ver, out, inv, prim $=$ dados médios do verão, outono, inverno e primavera respectivamente. Dados elaborados por equações de regressão linear desenvolvidas por Wrege et al. (2011), que relacionam as variáveis climáticas com as coordenadas geográficas latitude e longitude e a altitude, para os pontos de ocorrência de A. angustifolia. Fonte: Wrege et al. (2016).

Tabela 2. Área com potencial de ocorrência de araucária nas próximas décadas em função das mudanças climáticas globais.

\begin{tabular}{ccccccccc}
\hline \multirow{2}{*}{ Algoritmo } & Atual & Modelo / Cenário & \multicolumn{2}{c}{$2011-2040$} & \multicolumn{2}{c}{$2041-2070$} & \multicolumn{2}{c}{$2071-2100$} \\
\hline \multirow{3}{*}{ Niche Mosaic } & \multirow{2}{*}{37.851 .745} & RCP 4,5 & 20.125 .537 & $53,17 \%$ & 12.082 .853 & $31,92 \%$ & 9.353 .085 & $24,71 \%$ \\
& & RCP 8,5 & 12.708 .690 & $33,57 \%$ & 5.309 .659 & $14,02 \%$ & 92.809 & $0,24 \%$ \\
\cline { 3 - 8 } & \multirow{2}{*}{ Bioclim } & RCP 4,5 & 15.255 .154 & $52,06 \%$ & 7.903 .796 & $26,97 \%$ & 4.859 .523 & $16,58 \%$ \\
& & RCP 8,5 & 9.140 .391 & $31,19 \%$ & 2.823 .471 & $9,64 \%$ & 21.776 & $0,074 \%$ \\
\hline
\end{tabular}

$\mathrm{RCP}=$ Representative concentration pathways; RCP 4,5: cenário medianamente pessimista; RCP 8,5: cenário pessimista. Fonte: Wrege et al. (2016).
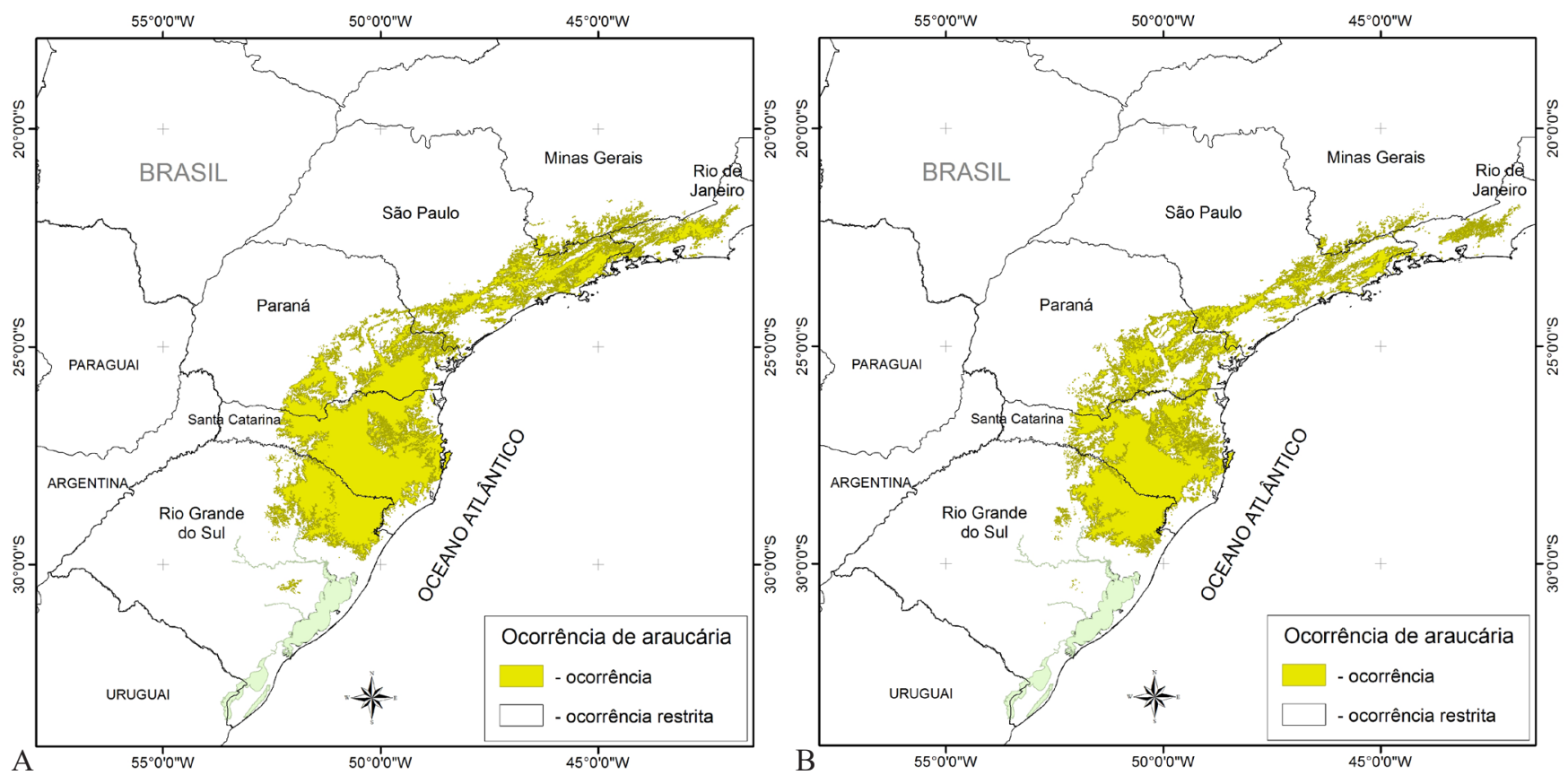

Figura 11. Alteração das regiões de ocorrência de araucária baseado no modelo Niche Mosaic de acordo com as mudanças climáticas globais - período 2011-2040, segundo Wrege et al. (2016). RCP = Representative concentration pathways. A - RCP 4,5 - cenário intermediário, B - RCP 8,5 - cenário pessimista. Nota: Latitude original: $0^{\circ}$ Equador, Longitude original: $54^{\circ} \mathrm{Sul}$, Datum: SAD69. Fonte: Divisas: IBGE (2011), Modelo digital de elevação: Geological Survey (1999), dados climáticos: INPE. 


\section{A. angustofolia e as mudanças climáticas globais}

Nas próximas décadas, com as mudanças climáticas globais e o consequente aumento de temperatura, será mais comum encontrar a araucária nas zonas de maior altitude e nas latitudes mais ao Sul, onde o clima será mais ameno e com maior umidade (Chou et al., 2014a), conforme pode ser observado nas Figuras 11 a 16, verificando-se uma retração nas zonas favoráveis para ocorrência da espécie, em parte também pela expansão das florestas vizinhas, compostas por espécies folhosas tropicais, mais eficientes que as espécies da Floresta Ombrófila Mista.

Em poucas décadas, deverão ocorrer grandes mudanças, podendo haver aumento de temperatura do ar entre $1,8{ }^{\circ} \mathrm{C}$ e $6,3{ }^{\circ} \mathrm{C}$, o que não tem precedentes históricos. Para compensar o aumento de temperatura, deverá haver um deslocamento das zonas favoráveis para o desenvolvimento das espécies de $240 \mathrm{~m}$ a $1.260 \mathrm{~m}$ de altitude acima da cota altimétrica atual, respectivamente, considerando-se que a cada $100 \mathrm{~m}$ de altitude ocorre, na prática, uma diminuição de $0,48{ }^{\circ} \mathrm{C}$ na temperatura do ar no estado de Santa Catarina (Fritzsons et al., 2016), ou de $0,75^{\circ} \mathrm{C}$, em média, no estado do Rio Grande do Sul (Fritzsons et al., 2015).

Em eras geológicas passadas, quando ocorreram mudanças climáticas globais, as alterações foram bem mais lentas, ao longo de centenas de gerações, permitindo que os mecanismos evolutivos da espécie atuassem. A escala atual de mudança passou de milhares de anos para, no máximo, 100 anos. Para a araucária, espécie de ciclo de vida longo, dependente do frio, de umidade elevada e da qualidade dos solos, o processo de adaptação poderá ser mais lento que a progressão das mudanças climáticas e a maioria dos efeitos negativos causados pelo declínio e fragmentação das populações da espécie serão evidentes apenas após algumas gerações (Sousa, 2000).

A araucária é uma espécie vulnerável às mudanças climáticas globais, devido ao seu sistema de reprodução, de germinação e de dispersão de sementes (Bittencourt \& Sebbenn, 2007), que podem resultar na redução de sua capacidade de regeneração e das taxas de crescimento. Sua vulnerabilidade pode ainda se tornar maior com o aumento dos riscos de ataque de insetos e de pragas, dos incêndios florestais e da competição com as espécies folhosas tropicais e as exóticas invasoras, as quais apresentam mecanismos de reprodução e crescimento mais eficientes. Portanto, a manutenção de sua diversidade genética é e será ainda mais importante para adaptação aos novos ambientes que ocorrerão nas próximas décadas, uma vez que representará a possibilidade de uma melhor resposta da espécie às mudanças climáticas globais.

\section{Estudos de conservação e melhoramento genético de $A$. angustifolia}

A. angustifolia é dotada de rico material genético, com populações distintas oriundas de microclimas diversos, o que contribui para a formação de variedades, raças locais ou ecotipos (Reitz \& Klein, 1966). Os microclimas, que tornam possível a manutenção da variabilidade genética da araucária, se devem à combinação das latitudes médias com o relevo de altitude, típicos das regiões serranas do Sul e do Sudeste do Brasil.

Apesar da importância econômica, ambiental e social da espécie, ainda não se encontram disponíveis estudos científicos em áreas do conhecimento que identifiquem essas variedades, raças locais ou ecotipos (ex: taxonomia, filogenia, genética de populações, etc.). Embora a Embrapa Florestas e seus parceiros tenham iniciado um programa de melhoramento genético da espécie à partir dos testes de procedências e progênies, estabelecidos na década de 1980, não se conhecem outros trabalhos expressivos envolvendo uma maior representatividade da espécie. Esses testes foram analisados, inicialmente, à partir da genética quantitativa e posteriormente com o emprego de marcadores bioquímicos e moleculares, os quais têm contribuído para o andamento do programa de melhoramento e conservação genética.

Estudos de genética de populações, a maioria pontuais, têm sido conduzidos, à partir do ano 2000, através de marcadores bioquímicos e moleculares. Estes estudos revelaram diferenças genéticas entre e dentro de populações (Shimizu et al., 2000; Sousa, 2001; Auler et al., 2002; Mantovani et al., 2006; Puchalski et al., 2006; Stefenon, 2007; Bittencourt \& Sebbenn, 2007). Com base nesses trabalhos e análises mais recentes, foram identificados dois grupos distintos genetica e ambientalmente: um situado onde a espécie ocorre, nos estados de São Paulo e Minas Gerais, entre as latitudes $19^{\circ} 15^{\prime} \mathrm{S}$ e $27^{\circ} 23^{\prime} \mathrm{S}$ e, muito raramente, nos estados do Rio de Janeiro e do Espírito Santo; outro situado na região Sul, entre as latitudes $27^{\circ} 23^{\prime} \mathrm{S}$ e $31^{\circ} 30^{\prime} \mathrm{S}$, ao sul do trópico de Capricórnio, em altitudes superiores a $500 \mathrm{~m}$, nas regiões serranas situadas entre o Sul do 
estado do Paraná e o Norte do estado do Rio Grande do Sul (Hueck, 1972; Fähser, 1981; Carvalho, 1994;

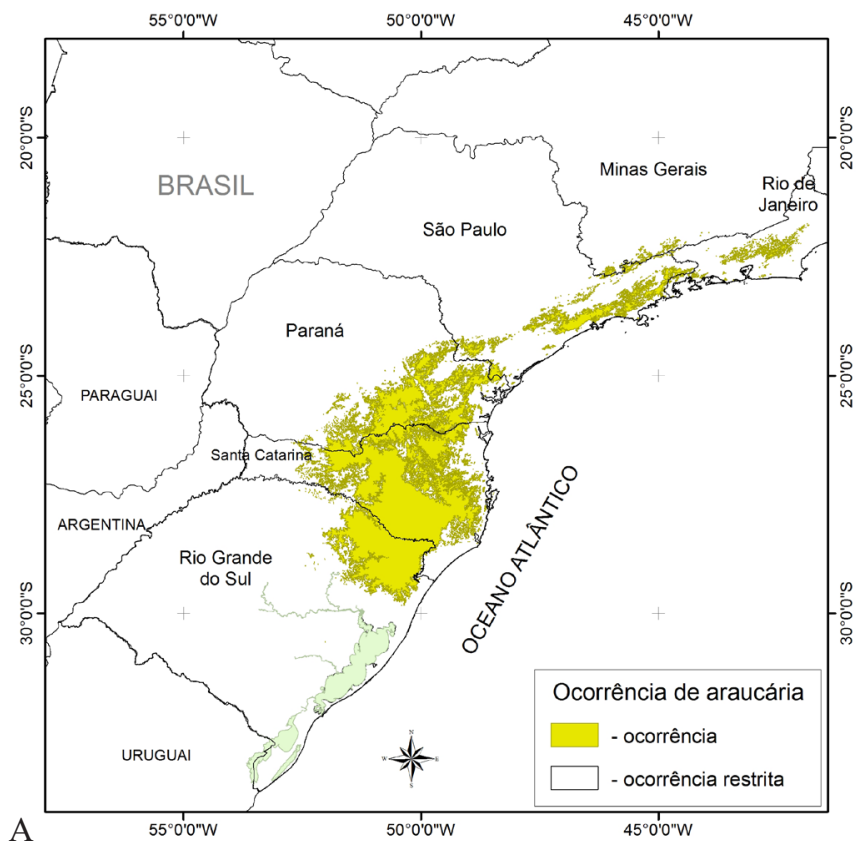

Valgas, 2008; Valgas et al., 2009; Sousa et al., 2009; Sousa \& Richards, 2011), entre as longitudes $41^{\circ} 30^{\prime}$ W e $54^{\circ} 30^{\prime} \mathrm{W}$.

Figura 12. Alteração das regiões de ocorrência de araucária baseado no modelo Niche Mosaic de acordo com as mudanças climáticas globais - período 2041-2070, segundo Wrege et al. (2016). RCP = Representative concentration pathways. A - RCP 4,5 - cenário intermediário, B - RCP 8,5 - cenário pessimista Nota: Latitude original: $0^{\circ}$ Equador, Longitude original: $54^{\circ} \mathrm{Sul}$, Datum: SAD69. Fonte: Divisas: IBGE (2011), Modelo digital de elevação: Geological Survey (1999), dados climáticos: INPE.
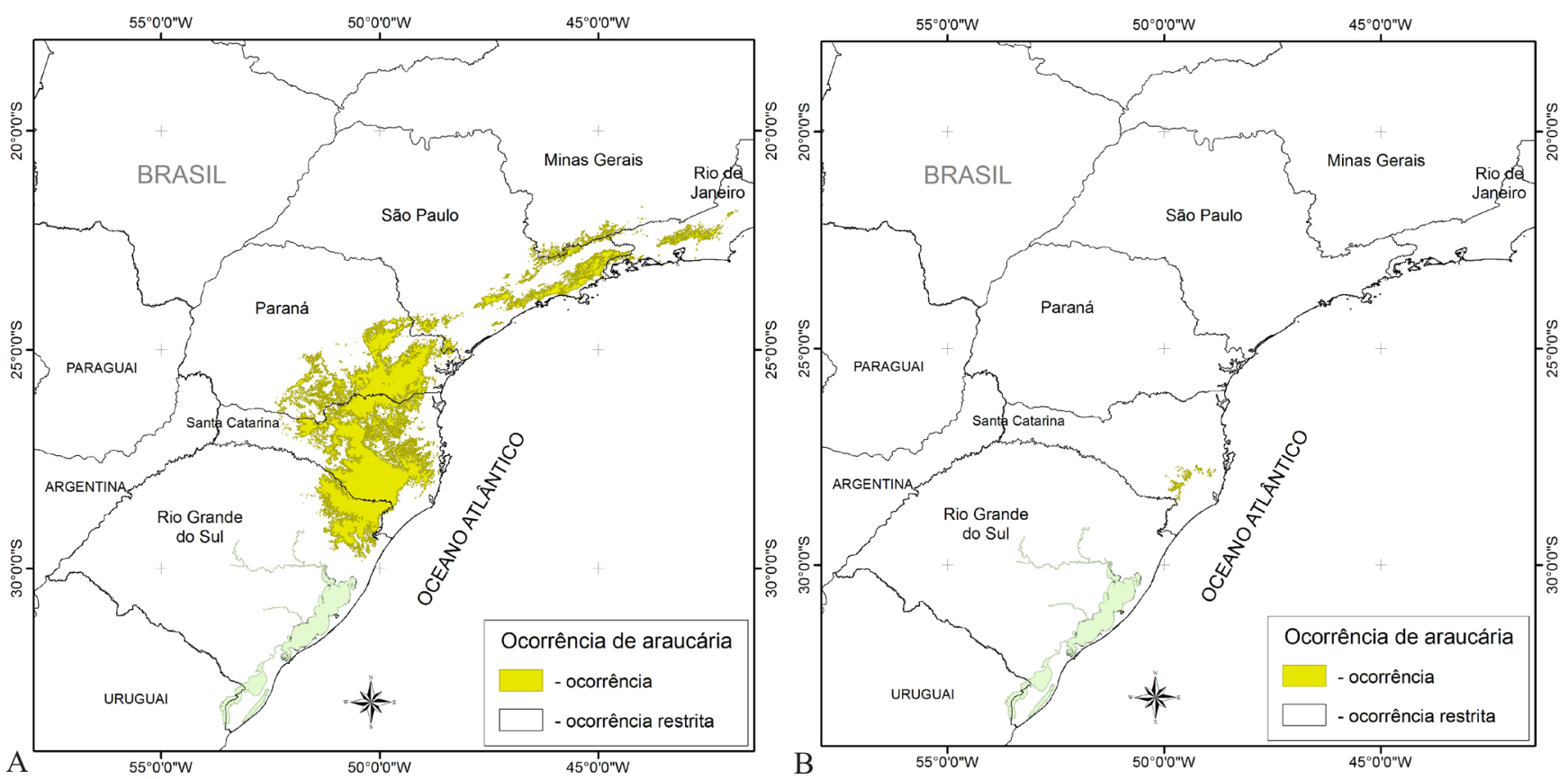

Figura 13. Alteração das regiões de ocorrência de araucária baseado no modelo Niche Mosaic de acordo com as mudanças climáticas globais - período 2071-2100, segundo Wrege et al. (2016). RCP = Representative concentration pathways. A - RCP 4,5 - cenário intermediário, B - RCP 8,5 - cenário pessimista Nota: Latitude original: $0^{\circ}$ Equador, Longitude original: $54^{\circ} \mathrm{Sul}$, Datum: SAD69. Fonte: Divisas: IBGE (2011), Modelo digital de elevação: Geological Survey (1999), dados climáticos: INPE. 

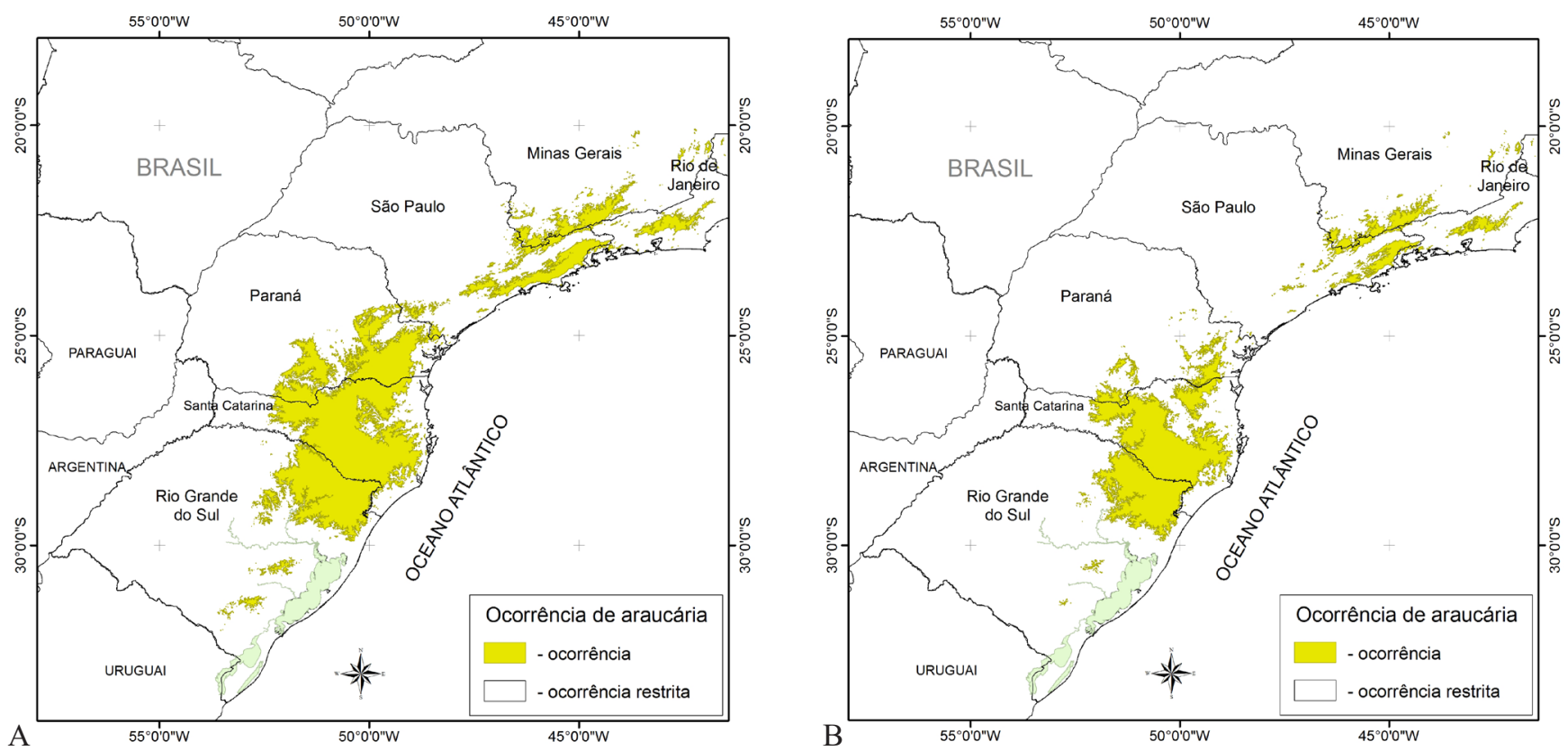

Figura 14. Alteração das regiões de ocorrência de araucária baseado no modelo Bioclim de acordo com as mudanças climáticas globais - período 2011-2040, segundo Wrege et al. (2016). $\mathrm{RCP}=$ Representative concentration pathways. A - RCP 4,5 - cenário intermediário, B - RCP 8,5 - cenário pessimista Nota: Latitude original: $0^{\circ}$ Equador, Longitude original: $54^{\circ}$ Sul, Datum: SAD69. Fonte: Divisas: IBGE (2011), Modelo digital de elevação: Geological Survey (1999), dados climáticos: INPE.
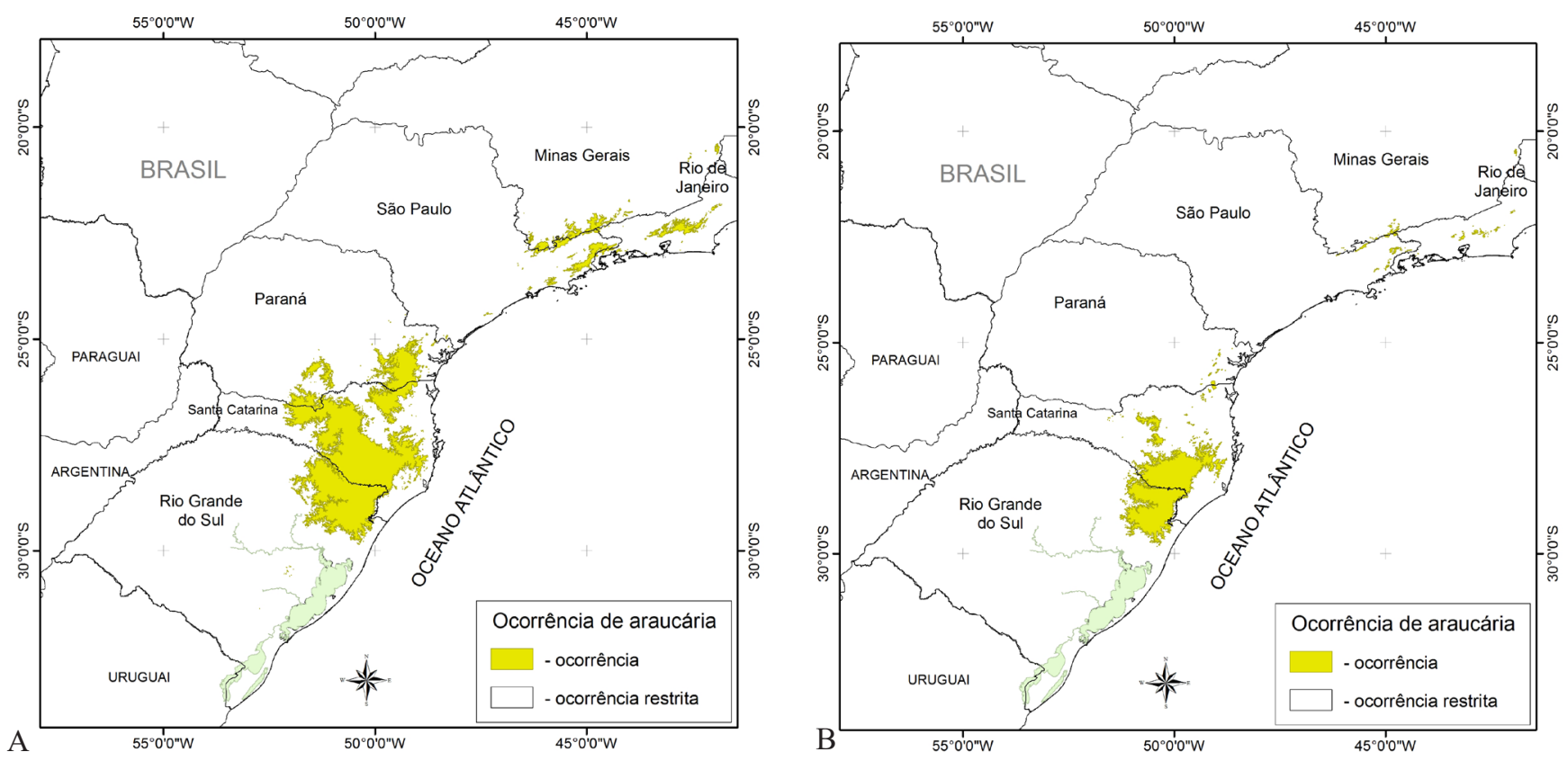

Figura 15. Alteração das regiões de ocorrência de araucária baseado no modelo Bioclim de acordo com as mudanças climáticas globais - período 2041-2070, segundo Wrege et al. (2016). RCP = Representative concentration pathways. A - RCP 4,5 cenário intermediário, B - RCP 8,5 - cenário pessimista Nota: Latitude original: $0^{\circ}$ Equador, Longitude original: $54^{\circ} \mathrm{Sul}$, Datum: SAD69. Fonte: Divisas: IBGE (2011), Modelo digital de elevação: Geological Survey (1999), dados climáticos: INPE. 

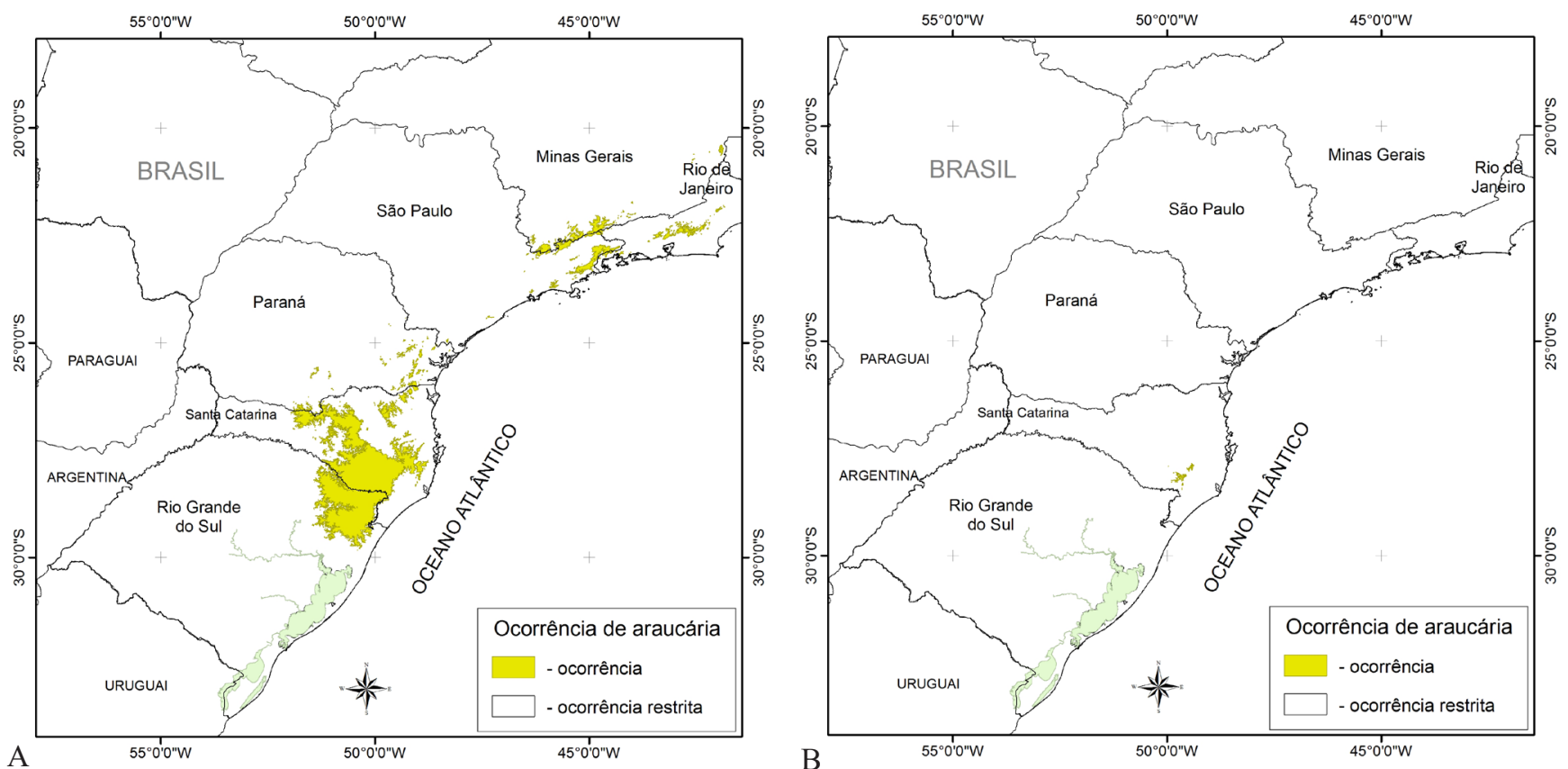

Figura 16. Alteração das regiões de ocorrência de araucária baseado no modelo Bioclim de acordo com as mudanças climáticas globais - período 2071-2100, segundo Wrege et al. (2016). RCP = Representative concentration pathways. A - RCP 4,5 - cenário intermediário, B - RCP 8,5 - cenário pessimista Nota: Latitude original: $0^{\circ}$ Equador, Longitude original: $54^{\circ}$ Sul, Datum: SAD69. Fonte: Divisas: IBGE (2011), Modelo digital de elevação: Geological Survey (1999), dados climáticos: INPE.

\section{Conclusões}

Os trabalhos que estão sendo feitos de modelo de nicho e genética de populações poderão contribuir para o aperfeiçoamento dos programas de melhoramento genético da araucária, indicando a existência dos grupos de populações em campo com as características genéticas mais desejadas para o melhoramento e, ainda, poderão indicar as melhores condições para o desenvolvimento da araucária, de acordo com o material genético de cada região.

As mudanças climáticas globais poderão trazer ameaças à araucária, reduzindo a sua área de ocorrência natural drasticamente, principalmente com o aumento de temperatura e alteração no regime hídrico, reduzindo o seu potencial de sobrevivência e estabelecimento em novas áreas de plantio.

Os estados do Espírito Santo, Rio de Janeiro, Minas Gerais, São Paulo e Paraná deverão ter grande perda de área potencial de araucária nas próximas décadas, nesta ordem de importância. As regiões serranas de maior altitude do Paraná, de Santa Catarina e do Rio Grande do Sul também devem ser priorizadas para preservação, para garantir a sobrevivência das populações locais.
As projeções aqui apresentadas devem ser avaliadas levando-se em consideração outros fatores que interferem no desenvolvimento da espécie. Certamente, o cenário atual não será o mesmo com o aumento da temperatura e alteração do padrão de chuvas, o que sugere a importância de um acompanhamento das populações de araucária nas próximas décadas.

A criação de áreas de conservação ou preservação ambiental poderá ajudar a proteger a araucária da extinção, principalmente para populações especiais (exemplo, o extremo Sul do Rio Grande do Sul, por se tratar de um ambiente muito diferente dos demais) e outras populações encontradas em fragmentos mais ao Norte da região de ocorrência, que apresentam características diferentes.

\section{Agradecimentos}

Sr. Adão da Costa Gülich, diretor da Flona de Passo Fundo (RS); Sra. Edenice Brandão de Ávila, diretora da Flona de São Francisco de Paula (RS); Sr. Léo Nascimento, diretor do Parque Nacional do Itatiaia (RJ); À Embrapa, pelo Projeto Araucamate. 


\section{Referências}

Anjos, L. dos. O ciclo anual de Cyanocorax caeruleus em floresta de araucária (Passeriformes: Corvidae). Ararajuba, v. 2, n. 1, p. 19-23, 1991.

Auler, N. M. F. et al. The genetics and conservation of Araucaria angustifolia: genetic structure and diversity of natural populations by means of non-adaptative variation in the state of Santa Catarina, Brazil. Genetics and Molecular Biology, v. 25, n. 3, p. 239-338, 2002. DOI: 10.1590/S1415-47572002000300014.

Behling, H. et al. Late holocene vegetation history and early evidence of Araucaria angustifolia in Caçapava do Sul in the lowland region of Rio Grande do Sul State, Southern Brazil. Brazilian Archives of Biology and Technology, v. 59, 2016. DOI: 10.1590/1678-43242016150264.

Behling, H. et al. Late quaternary araucaria forest, grassland (Campos), fire and climate dynamics, studied by high-resolution pollen, charcoal and multivariate analysis of the Cambará do Sul core in Southern Brazil. Palaeogeography, Palaeoclimatology, Palaeoecology, v. 203, n. 3-4, p. 277-297, 2004. DOI: 10.1016/ S0031-0182(03)00687-4.

Behling, H. \& Pillar, V. D. Late quaternary vegetation, biodiversity and fire dynamics on the southern Brazilian highland and their implication for conservation and management of modern Araucaria forest and grassland ecosystems. Philosophical Transactions of the Royal Botanic Society, v. 362 B, p. 243-251, 2007. DOI: 10.1098/ rstb.2006.1984.

Bittencourt, J. V. M. \& Sebbenn, A. M. Patterns of pollen and seed dispersal in a small, fragmented population of the wind-pollinated tree Araucaria angustifolia in southern Brazil. Heredity, v. 99, p. 580-591, 2007. DOI: 10.1038/sj.hdy.6801019.

Carlucci, M. B. et al. Conservação da floresta com araucária no extremo sul do Brasil. Natureza e Conservação, v. 9, n. 1, p. 111114, 2011. DOI: 10.4322/natcon.2011.015.

Carlucci, M. B. et al. Individual-based trait analyses reveal assembly patterns in tree sapling communities. Journal of Vegetation Science, v. 23, p. 176-186, 2012. DOI: 10.1111/j.1654-1103.2011.01339.x.

Carvalho, P. E. R. Espécies florestais brasileiras: recomendações silviculturais, potencialidades e uso da madeira. Colombo: EMBRAPA-CNPF; Brasília, DF: EMBRAPA-SPI, 1994. 639 p.

Cavalcanti, M. P. Distribuição dos pinheirais no Brasil. [S.1.]: Sociedade Nacional de Agricultura, 1908.

Centro de Referência em Informação Ambiental. Species link. Disponível em: <http://splink.cria.org.br/>. Acesso em 7 dez. 2015.

Chou, S. C. et al. Assesment of climate change over South America under RCP 4.5 and 8.5. downscaling scenarios. American Journal of Climate Change, v. 3, p. 512-525, 2014a. DOI: 10.4236/ ajcc.2014.35043.

Chou, S. C. et al. Evaluation of the eta simulation nested in three global climate change models. American Journal of Climate Change, v. 3, p. 438-454, 2014b. DOI: 10.4236/ajcc.2014.35039.

Conceição, D. M. da et al. Novo registro de floresta petrificada em Altos, Piauí: relevância e estratégias para geoconservação. Pesquisas em Geociências, v. 43, p. 311-324, 2016.
Duarte, L. S. et al. Plant dispersal strategies and the colonization of Araucaria forest patches in a grassland-forest mosaic. Journal of Vegetation Science, v. 18, p. 847-858, 2007. DOI: 10.1111/j.16541103.2007.tb02601.x.

Dümig, A. et al. Araucaria forest expansion in the southern Brazilian highlands as revealed by $14 \mathrm{C}$ and $\delta 13 \mathrm{C}$ studies. Geoderma, v. 145, p. 143-157, 2008.

Dutra, T. L. \& Stranz, A. História das Araucariaceae: a contribuição dos fósseis para o entendimento das adaptações modernas da família no hemisfério sul, com vistas a seu manejo e conservação. In: Ronchi, L. H. \& Coelho, O. G. W. (Org.). Tecnologia, diagnóstico e planejamento ambiental. São Leopoldo: Ed. da UNISINOS, 2003. p. 293-351.

Fähser, L. Die Bewirtschaftung der letzten Brasil-KieferNaturwälder, eine entwicklungspolitische Aufgabe. Forstarchiv, v. 52, p. 22-26, 1981.

Fritzsons, E. et al. Altitude e temperatura: estudo do gradiente térmico no Rio Grande do Sul. Revista Brasileira de Climatologia, v. 16, p. 108-119, 2015. DOI: 10.5380/abclima.v16i0.39665.

Fritzsons, E. et al. Relação entre altitude e temperatura: uma contribuição ao zoneamento climático no estado de Santa Catarina, Brasil. Revista Brasileira de Climatologia, v. 18, p. 80-92, 2016. DOI: 10.5380/abclima.v18i0.39471.

Geological Survey (U. S.). Survey National Mapping Division. Global 30 arc second elevation data. 1999. Disponível em: $<$ https:// lta.cr.usgs.gov/GTOPO30>. Acesso em: 10 jul. 2015.

Giongo, C. \& Waechter, J. L. Composição florística e espectro de dispersão das espécies arbóreas de uma floresta mista com Podocarpus, Rio Grande do Sul. Revista Brasileira de Biociências, v. 5, n. 2, p. 333-335, 2007.

Gonçalves, E. T. \& Souza, A. Floristic variation in ecotonal areas: patterns, determinants and biogeographic origins of subtropical forests in South America. Austral Ecology, v. 39, p. 122-134, 2014.

Hueck, K. As florestas da América do Sul. Brasília: Ed. da UnB; São Paulo: Polígono, 1972. 466 p.

Hueck, K. Distribuição e habitat natural do pinheiro do paraná (Araucaria angustifolia). Boletim da Faculdade de Filosofia, Ciências e Letras, Universidade de São Paulo. Botânica, v. 10, p. 5-24, 1953. DOI: 10.11606/issn.2318-5988.v10i1p5-24.

IBGE. Malha municipal do Brasil, 2011. Rio de Janeiro, 2011. CD-ROM.

IUCN Red List of Threatened Species. Red list: version 2016-3. Disponível em: <www.iucnredlist.org>. Acesso em: 18 fev 2017.

James, P. E. Latin America. New York: Odyssey Press, 1942.

Klein, R. M. Aspectos dinâmicos da vegetação do sul do Brasil. Sellowia, v. 36, p. 5-54, 1984.

Klein, R. O aspecto dinâmico do pinheiro brasileiro. Sellowia, v. 12, p. 17-48, 1960.

Lamberts, A. V. D. H. Predação e sobrevivência de sementes de Araucaria angustifolia (Bert.) Kuntze em áreas de mata nativa e plantação de Pinus eliottii na Floresta Nacional de São Francisco de Paula, RS. 2003. Dissertação (Mestrado em Ecologia) - Universidade Estadual de Campinas, Campinas. 
Leite, P. F. Contribuição ao conhecimento fitoecológico do sul do Brasil. Ciência e Ambiente, v. 24, p. 51-73, 2002.

Lima, L. et al. Matas de Araucaria angustifolia em áreas do escudo Sul-riograndense. Paleontologia em Destaque, v. 17, n. 40, p. 18, 2002.

Mantovani, A. et al. Internal genetic structure and outcrossing rate in a natural population of Araucaria angustifolia (Bert.) O. Kuntze. Journal of Heredity. v. 97, n. 5, p. 466-472, 2006. DOI: 10.1093/ jhered/es1031.

Navas, C. A. \& Cruz-Neto, A. Se extinções associadas a mudanças climáticas globais são eventos naturais, por que devemos nos preocupar com o cenário atual? Revista de Biologia, v. 1, p. 9-11, 2008 .

Puchalski, A. et al. Variações em populações naturais de Araucaria angustifolia (Bert.) O. Kuntze associada a condições edafoclimáticas. Scientia Florestalis, v. 70, p. 137-148, 2006.

Rambo, B. O Elemento andino no pinhal riograndense. Anais Botânicos do Herbário Barbosa Rodrigues, v. 2, n. 2, p. 125-136, 1951.

Reitz, R. \& Klein, R. M. Araucariáceas. Itajai: Herbário Barbosa Rodrigues, 1966. 62 p. (Flora ilustrada catarinense).

Reitz, R. et al. Projeto madeira do Rio Grande do Sul. Porto Alegre: Sudesul, 1988. $525 \mathrm{p}$.

Rühle, K. Die vegetationsformen suedamerikas in ihrer klimatischen bedingtheit. Petermans Mitt, 1928. 74 p.

Shimizu, J. Y. et al. Variabilidade genética em uma população remanescente de Araucária no Parque Nacional do Iguaçu, Brasil. Boletim de Pesquisa Florestal, v. 41, p. 18-36, 2000.

Sousa, V. A. et al. Genetic differentiation among araucaria populations in Brazil. In: CONGRESO FORESTAL MUNDIAL, 13., 2009, Buenos Aires. Desarrollo forestal: equilibrio vital. Argentina: FAO, 2009. Resumo.

Sousa, V. A. Population genetic studies in Araucaria angustifolia (Bert.) O. Kuntze. 2001. 161 f. Thesis (PhD) - Faculty of Forest Sciences and Forest Ecology, Institute of Forest Genetics and Forest Tree Breeding, Georg-August University of Göttingen, Göttingen.

Sousa, V. A. Population genetic studies in Araucaria angustifolia in southern Brazil. Heredity, n. 99, p. 580-591, 2000.

Sousa, V. A. \& Richards, C. M. Genetic diversity and biogeographic determinants of population structure in Araucaria angustifolia Bert. O Ktze. In: WORKSHOP OF EMBRAPA 'S SCIENTISTS IN USA, 1., 2011, Fort Collins. Washington: Labex USA, 2011. p. 37.
Stefenon, V. M. The distribution of the genetic diversity in Arucaria angustifolia and its implications for the genetic conservation of the species'genetic resources. 2007. $120 \mathrm{f}$. Thesis $(\mathrm{PhD})$ - Faculty of Forest Sciences and Forest Ecology, Institute of Forest Genetics and Forest Tree Breeding, Georg-August University of Göttingen, Göttingen.

Teixeira, M. B. et al. Vegetação. In: PROJETO RADAMBRASIL. Folha SH.22 Porto Alegre parte das folhas SH. 21 Uruguaiana e SI. 22 Lagoa Mirim: geologia, geomorfologia, pedologia, vegetação, uso potencial da terra. Rio de Janeiro: Departamento Nacional da Produção Mineral, 1986. p. 541-632. (Levantamento de recursos naturais, v. 33).

Thomas, P. Araucaria angustifolia. The IUCN Red List of Threatened Species, 2013. DOI: 10.2305/IUCN.UK.2013-1.RLTS. T32975A2829141.en.

Valgas, R. A. Análise multivariada aplicada no mapeamento da divergência genética de subpopulações de Araucaria angustifolia por marcadores isoenzimáticos. 2008. 139 f. Dissertação (Mestrado em Ciências) - Universidade Federal do Paraná.

Valgas, R. A. et al. Cluster analysis applied in mapping the genetic divergence of populations of Araucaria angustifolia (Bert.) O. Kuntze by isoenzymatic markers. In: Recent advances in mathematics and computers in biology and chemistry: proceedings of the 10th WSEAS International Conference on Mathematics and Computers in Biology and Chemistry, Prague, Czech Republic, 2009. [S.1.]: WSEAS Press, 2009. p. 87-91.

World Meteorological Organization. The global climate 2001-2010: a decade of climate extremes: summary report. Geneva, 2013. 8 p.

Wrege, M. S. et al. Atlas climático da região Sul do Brasil: Estados do Paraná, Santa Catarina e Rio Grande do Sul. Pelotas: Embrapa Clima Temperado; Colombo: Embrapa Florestas, 2011. 336 p.

Wrege, M. S. et al. Climate change and conservation of Araucaria angustifolia in Brazil. Unasylva, v. 60, n. 231/232, p. 30-33, 2009.

Wrege, M. S. et al. Predicting Current and Future geographical distribution of Araucaria niche modeling. Environmental and Ecology Research, v. 4, p. 269-279, 2016. DOI: 10.13189/ eer.2016.040506

Wrege, M. S. et al. Variáveis climáticas relacionadas aos serviços ambientais: estudo de caso da araucária. In: Parron, L. M. et al. (Org.). Serviços ambientais em sistemas agrícolas e florestais do Bioma Mata Atlântica. Brasília, DF: Embrapa, 2015 p. 242-247. 